\section{THU0504 QUANTIFYING PHYSICAL EDUCATION ATTENDANCE AND ITS RELATIONSHIP TO PAIN SEVERITY AND FATIGUE IN ADOLESCENTS WITH JUVENILE IDIOPATHIC ARTHRITIS - RESULTS FROM THE GERMAN NATIONAL PAEDIATRIC RHEUMATOLOGICAL DATABASE}

F. Milatz $^{1}$, M. Niewerth ${ }^{1}$, N. Geisemeyer ${ }^{1}$, J. Peitz ${ }^{2}$, C. Rietschel ${ }^{3}$, T. Lutz $^{4}$, A. Holl-Wieden ${ }^{5}$, K. Minden ${ }^{1,6}$. ${ }^{1}$ Epidemiology Unit, German Rheumatism Research Center Berlin, Berlin; ${ }^{2}$ Pediatric Rheumatology Centre, Asklepios Clinic, Sankt Augustin; ${ }^{3}$ Pediatric Rheumatology, Clementine Children's Hospital, Frankfurt/Main; ${ }^{4}$ Medical Centre for Children and Adolescents, University Hospital Heidelberg, Heidelberg; ${ }^{5}$ Children's Hospital, University Hospital Würzburg, Würzburg; ${ }^{6}$ Children's University Hospital, Charité University Hospital, Berlin, Germany

Background: Regular physical education (PE) can help adolescents achieve the recommended amount of daily physical activity and provide immediate health benefits, by positively affecting musculo-skeletal development, mental health and social behavior. Adolescents with juvenile idiopathic arthritis (JIA) are less physically active and have lower fitness levels than their healthy peers [1]. Moreover, pain and fatigue are one of the most frequent complaints and identified as one of the causes behind impaired (social) functioning [2].

Objectives: To describe the participation rate in PE and to assess its relationship to pain and fatigue in adolescents with JIA.

Methods: Cross-sectional data of adolescents with JIA recorded in the National Paediatric Rheumatological Database (NPRD) in the year 2015 were considered for the analyses. Disease characteristics were provided by rheumatologists along with patient-reported outcomes and participation in PE. Relationship to PE was assessed by using spearman's correlation.

Results: In 2015, a total of 3,289 adolescents with JIA (females 66\%, mean disease duration 5 years, persistent oligoarthritis $30 \%$ ) aged 13 to 17 were recorded. About $60 \%$ of the patients reported to participate in PE "always" ( $56 \%$ of girls, $69 \%$ of boys), whereas about $18 \%$ stated to be fully exempt from participating in PE (20\% of girls, $14 \%$ of boys). Significant differences were observed among JIA subtypes, whereby patients with enthesitis-related arthritis participated more frequently than patients with rheumatoid factor-positive polyarthritis (64\% vs. $46 \%$ ). The mean pain level was 2.1 , the mean fatigue level 1.8. Participation in PE was negatively correlated with self-reported pain intensity $(r=-0.43)$ and fatigue $(r=-0.32)$. Significant associations were found between PE attendance and age, sex, disease duration, functional status as well as disease activity measured by CHAQ and JADAS3-10, respectively $(p<0.05)$.

Conclusions: 6 of 10 adolescents with JIA participate in PE always, whereby higher rates of self-reported attendance are associated with less severe pain and fatigue. Since exercise programs in JIA lead to significant improvements in quality of life, it is likely that physical education attendance plays an important role in pain reduction and social functioning improvement in JIA.

\section{References:}

[1] van Brussel $\mathrm{M}$ et al. Aerobic and anaerobic exercise capacity in children with juvenile idiopathic arthritis. Arthritis Rheum 2007;57:891-7.

[2] Eyckmans $L$ et al. What does it mean to grow up with juvenile idiopathic arthritis? A qualitative study on the perspectives of patients. Clin Rheumatol. 2011;30:459-65.

Acknowledgements: The National Paediatric Rheumatological Database has been funded by the German Children Arthritis Foundation (Deutsche KinderRheumastiftung)

Disclosure of Interest: F. Milatz: None declared, M. Niewerth: None declared, N. Geisemeyer: None declared, J. Peitz: None declared, C. Rietschel: None declared, T. Lutz: None declared, A. Holl-Wieden: None declared, K. Minden Speakers bureau: Pfizer, Roche, Pharm-Allergan

DOI: 10.1136/annrheumdis-2017-eular.4744

\section{THU0505 LOW LITERACY BUT NOT PARENTAL SMOKING OR BREAST FEEDING WORSENS OUTCOME IN JUVENILE IDIOPATHIC ARTHRITIS IN A LOW INCOME POPULATION}

F.A.C. Rocha ${ }^{1}$, J.I. Vasques ${ }^{1}$, L.N. Rocha ${ }^{1}$, M.G. Aguiar ${ }^{1}$, J.P.E. Accioly ${ }^{1}$ C.N. Lechiu ${ }^{1}$, L.H.A. Costa ${ }^{1}$, M.F.C.D. Silva ${ }^{2}$, A.R.X. Feitosa ${ }^{2}$, H.A.L. Rocha ${ }^{3}$, C.N. Rabelo Jr. ${ }^{2} .{ }^{1}$ Internal Medicine, Universidade Federal Do Ceara; ${ }^{2}$ Pediatric Rheumatology, Hospital Geral de Fortaleza: ${ }^{3}$ Health Department, Universidade Federal Do Ceara, Fortaleza - CE, Brazil

Background: JIA data from underdeveloped regions are scant. We evaluated JIA patients living in low latitude ( $3^{\circ} 43^{\prime} S$ ), highly exposed to sunlight. We have shown their mean serum vitamin D levels as the higher ever reported, being not associated to disease status. Here are data on monthly income, breastfeeding, parental smoking, and literacy in this JIA cohort.

Methods: Clinical and demographic data [n (\%)] from 165 JIA patients followed between May 2015 - Dec 2016 in two reference outpatient centers in FortalezaCE Brazil were consecutively collected. Family income (more or less than 300 US $\$$ /month), breast feeding (more or less than 3 months), literacy [more or less than 8 school-years (SY)], and parental smoking (present/absent) were compared using Juvenile Arthritis Disease Activity Score (JADAS27), Childhood Health Assessment Questionnaire (CHAQ) and presence of deformities as prognostic outcomes.
Results: Mean age was 14 \pm 4.9 years with 94 (56.9); 63 (38), 40 (24), 37 (22.4), 19 (11.5), 5 (3), and 1 (0.6) of the polyarticular, enthesitis-related, oligoarticular, systemic, undifferentiated, and psoriatic categories, respectively. Mean total $\mathrm{CHAQ}$ was $0.4 \pm 0.58$ with a trend to be higher in polyarticular $(0.55 \pm 0.69)$ than oligoarticular $(0.3 \pm 0.4)$ category as well as higher JADAS 27 and more deformities in the former. Among 97 respondents, all but one patient was ever breastfed with 71 (73) for more than 3 months; 15 (17) out of 86 mothers were smokers and 28 (33.7) out of 83 smoked among family respondents; 49 (56.3) out of 87 parents had less than 8 SY and only 3 had superior level; 32 (37.6) out of 85 respondents earned less than 300 US $\$$. Lower literacy was associated to worse CHAQ ( $p=0.021)$. Neither maternal/family smoking nor breastfeeding time was associated to outcome. Lower income per se did not affect outcome.

Conclusions: This is the largest JIA database coming from an equatorial region reporting social and environmental aspects. Low literacy predominates, meaning more than half with less than elementary school, affecting prognosis. There is a low income profile and most family constituents do not smoke. Different from other countries, polyarticular category prevails despite low mean CHAQ vis-à-vis data from wealthy regions. Breast feeding for more than 1 month is almost universal and having breastfed for more than 3 months did not appear to influence prognosis

Acknowledgements: Conselho Nacional de Desenvolvimento Científico e Tecnológico - CNPq - Grant 459334/2014-0

Disclosure of Interest: None declared

DOI: 10.1136/annrheumdis-2017-eular.5190

\section{THU0506 ASSOCIATION OF NEUTROPHIL-TO-LYMPHOCYTE RATIO, PLATELET-TO-LYMPHOCYTE RATIO, PLATELET INDICES AND SERUM AMYLOID A LEVELS IN CHILDREN WITH FAMILIAL MEDITERRANEAN FEVER}

F. Dörtbas ${ }^{1}$, E. Comak ${ }^{2}$, E. Isıyel ${ }^{3} .{ }^{1}$ Rheumatology, Emsey Hospital, Istanbul; ${ }^{2}$ Pediatric Nephrology and Rheumatology, Akdeniz University, Antalya; ${ }^{3}$ Pediatric Nephrology and Rheumatology, Kocaeli Derince Training and Research Hospital, Kocaeli, Turkey

Background: Familial mediterranean fever (FMF) is an autosomal recessive, inherited, autoinflammatory disease characterized by recurrent, self-limited bouts of fever and inflammation. Persistent subclinical inflammation was related to increased risk of developing the serious complications, such as life- threatening amyloid a (AA) amyloidosis. The neutrophil-to-lymphocyte ratio (NLR), plateletto-lymphocyte ratio (PLR) and platelet indices [mean platelet volume (MPV) and platelet distribution width (PDW)] are simple, inexpensive, and useful markers to determine inflammation. Although, there have been a lots of data regarding inflammatory markers in FMF, little information was available the relationship between NLR, PLR, MPV and serum amyloid A levels.

Objectives: The aim of this study was to investigate association of NLR, PLR, platelet indices and serum amyloid A levels in children with FMF

Methods: The medical records of children with FMF were reviewed retrospectively. Information including demographic features, clinical and laboratory findings, SAA and C-reactive protein (CRP) levels, type of MEFV mutation were collected from the hospital's computerized database following approval by the local ethics commitee. The NLR and PLR were calculated from a complete blood count. Children ( $<7$ years old) was excluded from study due to age related features of neutrophil-to-lymphocyte ratio.

Results: Our study group included 127 children (60 males, 67 females) with FMF, diagnosed according to the Turkish pediatric FMF criteria. Their mean age was $11.35 \pm 3.69$ years, their mean age at time of disease onset was $8.73 \pm 3.93$ years, and their mean follow up period was $28.32 \pm 2.90$ months. Thirty two children (25.2\%) were homozygous, 56 children $(44.0 \%)$ were compound heterozygous and 39 children (30.7\%) were heterozygous for MEFV gene. In study population, the mean SAA levels, C-reactive protein (CRP) levels and erythrocyte sedimentation rate (ESR) were $9.21 \pm 13.88 \mathrm{mg} / \mathrm{L}, 1.38 \pm 2.31 \mathrm{mg} / \mathrm{dl}$ and $16.64 \pm 12.59 \mathrm{~mm} /$ hour, respectively. Significant positive correlations were found between SAA, ESR, CRP and NLR ( $r=0.2, p=0.02 ; r=0.28, p=0.001$; $r=0.32, p=0.001$, respectively). Hovewer, we did not find any significant correlation between SAA, ESR, CRP and platelet indices (MPV, PDW) and PLR (all p>0.05). Conclusions: Our finding suggest that simply calculating NLR from complete blood count may be used as an additional indicator of inflammation in children with FMF. But, platelet indices and PLR cannot be used as a laboratory markers predicting inflammation in these children.

Disclosure of Interest: None declared

DOI: 10.1136/annrheumdis-2017-eular.5149 